\title{
Форум Трансатлантическая безопасность 2020: устойчивость выходит на передний план
}

\section{Динос Кериган-Киру}

Координатор по кибербезопасности на Объединенном командно-штабном курсе Военного колледжа Сил обороны Ирландии, www.military.ie/en/who-weare/army/defence-forces-training-centre/the-military-college/

\begin{abstract}
Реэюме: В мероприятии Трансатлантическая безопасность 2020 приняли участие военные профессионалы и эксперты из широкого круга смежных дисциплин. Их цель состояла в том, чтобы обсудить и проанализировать как НАТО и его партнеры, включая Европейский Союз, могут развивать и укреплять способности для решения новых и возникающих вызовов безопасности. Онлайн форум состоялся вскоре после начала одной из величайших асимметричных проблем, с которыми мы сталкивались - пандемии COVID-19. Пандемия поставила под сомнение все предположения о том, что подразумевается под безопасностью и устойчивостью, которые у нас были после окончания Второй мировой войны. Имея это в виду, участники представили свои предложения о том, как мы можем адаптироваться и заранее предвидеть возникающие проблемы безопасности сейчас и в будущем. В этой статье резюмируются состоявшиеся обсуждения и выдвинутые предложения. Эти предложения включают гораздо более целостный подход к решению проблем безопасности, выходящий за рамки традиционного "разобщенного» или «ведомственного» подхода, к которому мы так привыкли.
\end{abstract}

Ключевые слова: НАТО, ЕС, асимметричный, возникающие вызовы безопасности, джем по безопасности.

Майский форум Безопасность 2020 был посвящен нетрадиционным вызовам. Что интересно, новаторские решения тоже нетрадиционны. Одним из наиболее ясных сигналов, которые возникли в результате джема, была 
необходимость разработки систем, процессов и институтов для прогнозирования и подготовки к будущим вызовам. Другими словами, выходить за видение проблем разрозненными в ведомственных и иерархических секторах и видеть более широкую, целостную картину. (На практике, об этом прямо говорилось 17 лет назад в главе 13 Доклада Комиссии по 11 сентября.) Это особенно верно, поскольку в ходе дискуссий было решительно доказано, что эти проблемы непредсказуемы или неизвестны - знаменитые «Неизвестные неизвестные». В ходе дебатов по шести тематическим областям акцент делался на обмене информацией, планировании и оказании помощи друг другу - как в НАТО, так и в Европейском союзе (EC), - чтобы помочь предотвратить возникновение вызовов безопасности и минимизировать их влияние, когда они уже появились. Особенное внимание было обращено на представление о необычных или асимметричных / гибридных вызовах, и было сочтено, что эти типы вызовов станут самым большим испытанием как для НАТО, так и для ЕС в ближайшие годы. Один из ключевых вопросов, который мы можем сформулировать в результате обсуждений, заключается в том, как все это помогает нам в НАТО - и ЕС - предвидеть новые вызовы? В частности, как это помогает в развитии устойчивости?

Темой всех обсуждений была возможность обмениваться информацией, чтобы иметь возможность “увидеть» новые вызовы безопасности, которые находятся на горизонте или даже за ним. Эти вызовы будут асимметричными по своей природе - такие пандемии, как COVID-19, но также и новые пандемии, о которых мы еще не знаем; экологические проблемы, включая изменение климата и плохое качество воздуха, ведущие к проблемам со здоровьем; терроризм в меняющихся формах; злонамеренные субъекты и государства, действующие вне норм в киберпространстве, дезинформация и фальшивые новости, исследования и разработки, кража интеллектуальной собственности и права человека во всем мире. Все это асимметричные или «необычные» проблемы, которые мы, возможно, еще не в состоянии решить с помощью «традиционных» политических и военных структур, созданных для холодной войны. Каковы возможные «нетрадиционные» решения нетрадиционных проблем для повышения устойчивости?

\section{Роль технологии}

В 2018 году представитель Палаты представителей США Уилл Херд обратил внимание на тот факт, что люди, работающие в финансовом секторе, часто лучше понимают спонсируемую государством киберпреступность, чем сами государственные спецслужбы. ${ }^{1}$ Конгрессмен Херд утверждал, что для противодействия новым угрозам необходим не только улучшенный обмен информацией между частным и государственным секторами, но и вся вера

12018 Aspen Cyber Summit. Доступно на https://www.aspeninstitute.org/events/ 2018-aspen-cyber-summit/. 
в то, что именно правительство понимает угрозы и вызовы лучше, чем бизнес, возможно, является устаревшим предположением. Как стало совершенно очевидно на джеме, когда мы имеем дело с новыми асимметричными вызовами, стирающими границы между военными и невоенными угрозами, эти старые убеждения, что «правительство знает больше», могут больше не иметь силы. Была выражена сильная поддержка более тесному сотрудничеству между компаниями, специализирующимися на технологиях, с одной стороны, и государством - с другой. В связи с этим было оспорено другое традиционное предположение: идея о том, что правительство - или такая организация, как НАТО или ЕС - имеет полное и всестороннее понимание конкретной проблемы безопасности, прежде чем объявить тендер для промышленности. На форуме было решительно высказано предположение, что правительства и международные организации могут не полностью понимать конкретную проблему безопасности, которую они хотят решить. Следовательно, необходимо гораздо более тесное сотрудничество с технологическими компаниями, чтобы они могли в первую очередь помочь определить проблему и действительно предложить возможные решения. Короче говоря, для того чтобы создать наиболее устойчивую среду, предположения о том, кто понимает лучше всего проблемы или вызовы безопасности, которые существовали десятилетиями, необходимо пересмотреть.

Искусственный интеллект (ИИ) рассматривался как центральный элемент сотрудничества с технологическими компаниями. Однако на джеме ясно было сказано, что ИИ хорош ровно настолько, насколько хороша исходная информация, которая вводится в систему. Ничто не заменит точные и ясные «наземные» данные, которые можно использовать в этих моделях искусственного интеллекта. Было приведено несколько примеров, когда ИИ был крайне неэффективен и даже опасен, когда в ИИ вводилась неверная информация. Хотя ИИ имеет решающее значение, он хорош настолько, насколько хороша информация, подтвержденная людьми - ничто не заменит разведку «на месте» для развития устойчивости.

Несмотря на настоятельный призыв к гораздо более интегрированному сотрудничеству ЕС и НАТО в оборонном секторе, было также признано значение не оборонных технологических компаний, таких как Facebook, Google, Apple и Amazon. В частности, тот факт, что традиционные компании из сектора безопасности могут больше не иметь монополии на знания, необходимые для обеспечения безопасности, особенно в областях возникающих проблем безопасности, выходящих за пределы «традиционных» военных границ. Как утверждалось на форуме, из-за этого НАТО и особенно ЕС (который имеет сильные регулирующие полномочия), возможно, потребуется изменить свои отношения с этими компаниями, переходя с модели «браконьер/лесничий» на более тесные отношения сотрудничества. Это вполне может способствовать огромному развитию в решении проблем безопасно- 
сти. Это также поможет решить новые и возникающие проблемы с помощью ИИ и, возможно со временем, квантовых вычислений. Это особенно важно, если европейские экономики хотят успешно противостоять китайским технологическим компаниям, таким как Tencent, Alibaba и Huawei.

\section{ЕС и НАТО - создание новых структур для совместной работы}

В то время как европейские страны (включая Великобританию) тратят на оборону больше, чем Россия и Китай вместе взятые, Европа в настоящее время сталкивается с серьезными проблемами, выступая в качестве единого игрока в сфере обороны. Это происходит из-за многократного дублирования оборонных программ по всей Европе и отсутствия единой оборонной стратегии и стратегии закупок, что снижает устойчивость и способность планировать и прогнозировать будущие вызовы безопасности. В связи с этим джем предложил идею «военной Шенгенской зоны», которая облегчает передвижение персонала и товаров по Европе, сокращает процедурные препятствия, опирается на успех Европейского оборонного агентства и постепенную военную интеграцию ЕС, происходящую в рамках Постоянного структурированного сотрудничества (EU PESCO).

Утверждалось, что для решения возникающих проблем безопасности необходимо значительно более интегрированное сотрудничество между НАТО и ЕС. Действительно, один из участников высказал предположение, что первоначальная «медленная реакция на COVID-19» (до того, как реакция значительно улучшилась) «подчеркивает некоторые недостатки как ЕС, так и НАTO». Все участники дискуссии согласились с тем, что международное сотрудничество и международное общество после COVID-19 должны основываться на нескольких основных принципах, в том числе:

- Объединение ресурсов и опыта;

- Реструктуризация власти и лидерства;

- Разработка гибких рамок, позволяющих лицам, принимающим решения в ЕС и НАTO, упростить и ускорить процесс принятия решений;

- Улучшение координации и обмена информацией между НАТО и ЕС, включая разработку механизмов раннего предупреждения и недопущение дублирования в ЕС / НАТО;

- Предоставление гражданам и всему населению возможности гораздо лучше осведомляться о возникающих вызовах безопасности;

- Развитие подхода «всего общества»;

- Лучшее сканирование горизонта на предмет угроз и повышение устойчивости к внешним воздействиям;

- Обеспечение лучшего понимания устойчивости, включая такие аспекты, как здоровье и общественное доверие; 
- Инвестировать в оборону, но осознавать, что вызовы безопасности носят как военный, так и «невоенный характер»;

- Совместная работа над созданием альтернативы дезинформации и недостоверной информации.

И у НАТО, и у ЕС есть свои собственные центры координации действий в чрезвычайных ситуациях - EADRCC ${ }^{2}$ (Евроатлантический координационный центр реагирования на стихийные бедствия) и ERCC $^{3}$ (Координационный центр реагирования на чрезвычайные ситуации). Было высказано мнение, что, хотя обе организации проделали выдающуюся работу, особенно во время COVID-19, у этих организаций гораздо больший потенциал. Участники дискуссии утверждали, что государства-члены НАТО и ЕС могли бы использовать эти два органа гораздо более эффективно, чем сейчас. Были выдвинуты идеи относительно того, как можно значительно упростить обращение к этим организациям с просьбой о действиях. Выдвинутая идея заключалась в том, что службы экстренного реагирования и региональные представители могли бы запросить действия EADRCC или ERCC напрямую, вместо того, чтобы запрашивать помощь через центральные правительственные каналы, что может занять несколько дней, когда остро требуется быстрое реагирование на чрезвычайную ситуацию. Таким образом, было решительно подтверждено, что EADRCC HATO и ERCC EC выполняют исключительную работу, но широкое понимание этих организаций и особенно способность на местах напрямую запрашивать помощь в чрезвычайных ситуациях требует разработки и оптимизации в самое ближайшее время.

\section{Новые европейские, трансатлантические и глобальные инсти-}

\section{туты для решения новых задач}

На форуме была особо подчеркнута роль институтов - как существующих, так и потенциальных. Конечно, в центре внимания этого анализа были НАТО и ЕС, как два основных института в мировых делах. Также особо был отмечен Гибридный центр передового опыта в Хельсинки. Интересно, что гибридный ЦПО не только решает проблемы гибридной устойчивости, но и сам по себе является гибридным учреждением. Любое государство ЕС или НАТО может стать его членом, но на самом деле это не институт НАТО или ЕС - он действует в «третьей сфере», вне прямого контроля НАТО или ЕС, что позволяет принимать дальновидные и динамичные решения. Джем пришел к общему заключению, что гибридный ЦПО имеет решающее значение для устойчивости ЕС и НАТО.

Джем также предложил новые институты, которые помогут решить развивающиеся проблемы безопасности, с которыми сталкиваются ЕС и НАТО,

2 NATO EADRCC, https://www.nato.int/cps/en/natohq/topics_117757.htm.

3 EU ERCC, https://ec.europa.eu/echo/what/civil-protection/emergency-responsecoordination-centre-ercc_en. 
и повысить устойчивость. Возможно, самым амбициозным предложением был «План Маршалла 2.0». Он будет сосредоточен на инвестициях в новые сектора и новую инфраструктуру. Ключевой частью будет существенное инвестирование в исследования и разработки, с особой поддержкой малых и средних компаний. Также было предложено создание Всемирной организации по пандемической безопасности для обеспечения эффективной координации, связи, гармонизации, планирования и всестороннего сотрудничества между странами и региональными альянсами.

В число других предложений по повышению устойчивости входили:

- «Форум НАТО - Тихоокеанский регион», включающий Альянс НАТО плюс Австралию, Японию, Новую Зеландию, Южную Корею и Колумбию для решения проблем со стороны Китая;

- Ц Центр передового опыта по сотрудничеству между НАТО и ЕС, основанный на действующих ЦПО НАТО, но с упором на то, как можно развивать и расширять сотрудничество между НАТО и ЕС;

- Борьба с фальшивыми новостями и дезинформацией: Целевая группа по стратегическим коммуникациям, предназначенная для противодействия влиянию на общественное мнение ЕС;

- Ц Ц Центр НАТО для стран Юга при Командовании объединенных сил в Неаполе, тесно сотрудничающий c EUROPOL (правоохранительные органы EC) и FRONTEX (пограничный контроль EC), а также с другими многонациональными центрами для создания антигибридной сети.

\section{Новые решения для повышения устойчивости могут выходить}

\section{за рамки исторически сложившегося подхода «национального} государства»

Форум также дал, может быть, некоторые неожиданные результаты.

Во время COVID-19 многие предлагали возродить национальное государство в качестве окончательного арбитра международной политики. Бытует мнение, что в дебатах национализма против глобализма именно национализм недавно вышел на первое место. Тем не менее, джем уделил огромное внимание и высказал доверие организациям, которые не являются национальными институтами, таким как Европейский центр передового опыта по противодействию гибридным угрозам (Гибридный ЦПО). Была выражена также решимость создать новые институциональные структуры для решения новых и возникающих проблем безопасности. Другими словами, как джем предположил, именно неадекватность государственных структур, возможно, помешала более гибкому и эффективному подходу.

\section{Нерешенные вопросы устойчивости}

Возможно, самый очевидный «нерешенный» вопрос: как именно будут реализованы предложенные идеи? Насколько они практичны? Задачу можно 
сформулировать так: «То, что хорошо выглядит на бумаге, так ли хорошо на практике?»

Каков график реализации этих предложений? Каким будет их бюджетирование и финансирование? Потребуется ли отдельным странам занимать деньги или такие учреждения, как ЕС, - или даже НАТО, - получат полномочия занимать деньги и финансировать инициативы? Как будут формироваться новые предлагаемые институты? Будут ли они действовать единогласно (как НАТО)? Будут ли они действовать на сочетании единогласия и голосования большинством (как в ЕС)? Каковы будут их правовые структуры - будут ли они полуавтономными от участвующих стран, как ЕС? Или они будут прямо отражать позиции участвующих стран, как НАТО? На деле, один из самых интересных нерешенных вопросов: должны ли эти новые институты состоять из участвующих национальных государств вообще, и если они не состоят из национальных государств, из чего они должны состоять? ЕС является примером организации, состоящей из государств-членов (Совет), прямой демократии граждан ЕС (Европейский парламент), исполнительной власти (Комиссия) и судебной власти (Европейский суд). Должны ли предлагаемые новые институты отражать эту систему? Или они должны быть похожи на НАТО, которое состоит только из государств-членов? Должен ли у них быть могущественный исполнительный орган (как например, Комиссия EC)? Что можно сказать о демократической подотчетности этих предлагаемых институтов? В общем, джем великолепно рассмотрел проблемы:

- Что представляют собой проблемы устойчивости и почему они важны?

- Каковы возможные решения по обеспечению устойчивости? Но остаются вопросы:

- Каким образом будут реализованы эти решения по обеспечению устойчивости?

- Когда это произойдет?

- Где это случится?

\section{Требуются всесторонние исследования осуществимости предла- гаемых идей по устойчивости}

Эти оставшиеся без ответа вопросы подводят нас к теме о том, какие дальнейшие исследования необходимы. Необходимы дополнительные исследования, чтобы:

- проанализировать внесенные предложения. Это важно, если НАТО и ЕС хотят оправдать ресурсы и время для реализации этих идей. Чрезвычайно важно, чтобы это исследование было объективным и беспристрастным для того, чтобы получить наилучший возможный анализ;

- понимать, как можно продвигать предложения. 
Темы, которые следует проанализировать, включают:

- ожидаемые выгоды в области человеческого развития, включая более широкие выгоды для общества, связанные с нашей способностью предвидеть вызовы безопасности на раннем этапе и эффективно решать эти проблемы;

- Финансовые затраты и финансовая выгода;

- Риски - особенно «непредвиденные последствия» - реализации предложений, внесенных во время джема;

- Общественная «поддержка» идей. В последние годы правительства обвиняли - правильно или ошибочно - в том, что они продвигают идеи, не консультируясь с населением и не понимая его проблем. Требуются исследования, чтобы убедиться, что идеи, предложенные на этом форуме, имеют отношение к озабоченностям общества. Какие консультации могут проводиться с общественными группами для дальнейшего развития этих идей? В самом деле, на джеме было специально подчеркнуто, что расширение прав и возможностей граждан и всего населения в плане гораздо большей ситуационной осведомленности о безопасности является ключом к развитию нашей безопасности. Необходимы дополнительные исследования того, как именно мы это делаем. Современный искусственный интеллект и компьютерное моделирование действительно могут значительно помочь в решении этой задачи, но они не заменяют тесных и комплексных консультаций с общественностью и заинтересованными сторонами, включая консультации с военными;

- Какова роль нынешних институтов, таких как Гибридный ЦПО (НАТО/ $\mathrm{EC)}, \mathrm{EADRCC}(\mathrm{HATO})$ и ERCC (EC)? Прежде чем вкладывать время и ресурсы в разработку новых предлагаемых институтов для повышения устойчивости, есть мнение, что мы могли бы исследовать дальнейшее расширение способностей - и возможное дальнейшее повышение автономии - уже существующих структур. Одним из предложений, выдвинутых на джеме, было применение модели гражданской готовности / устойчивости в нордическом стиле, которое могло бы стать моделью для ЕС и НАТО. Как такой «скандинавский подход" мог бы найти отражение в Европе и Северной Америке? Сделал бы такой подход недействительной необходимость создания новых институтов? Другими словами - можем ли мы работать с тем, что «у нас уже есть»? Или нам нужно создавать новые институты?

Данный форум выявил новые проблемы безопасности - не только возникающие из-за COVID-19, но и возможность того, что такие «неизвестные неизвестные» будут повторяться снова и снова в будущие годы. На нем были предложены четкие решения для повышения устойчивости, хотя 
требуются дополнительные исследования, чтобы выяснить, как эти решения могут быть реализованы на практике. Роль военных в этой новой среде, где четких границ [между войной и миром] больше не существует, невероятно неясна. Новые угрозы и вызовы выходят за рамки границ между военными и невоенными вызовами, и все же мы, в целом, действуем в рамках старых структур в новой среде, где эти старые предположения быстро рушатся.

Роль объективного стратегического анализа и консультирования, возможно, важна как никогда; такие организации, как Консорциум «Партнерство ради мира» (КПрМ), уже более двух десятилетий тесно сотрудничают с военными академиями и национальными правительствами во всех странах НАТО и странах-партнерах, а также почти во всех странах ЕС. Программа КПрМ определила ключевые аспекты изменений, и именно этот тип анализа имеет решающее значение, если мы хотим противостоять этим новым асимметричным угрозам и вызовам и стать устойчивыми. COVID-19 был не первой новой проблемой безопасности, с которой мы столкнулись, и, конечно же, не последней. Углубленный стратегический анализ, основанный на бесценных выводах джема Безопасность 2020, имеет решающее значение для решения проблем устойчивости, с которыми мы сейчас сталкиваемся.

\section{Отказ от ответственности}

Выраженные здесь взгляды являются исключительно взглядами автора и не отражают точку зрения Консорциума оборонных академий и институтов изучения безопасности ПрМ, участвующих организаций или редакторов Консорциума.

\section{Благодарность}

Журнал Connections: The Quarterly Journal, Vol. 19, 2020 издается при поддержке правительства США.

\section{Об авторе}

Динос Кериган-Киру, доктор философии, является приглашенным лектором по стратегической кибербезопасности в Университете Абертай, Шотландия. Он является инструктором по программе HATO DEEP (Программа повышения квалификации в области обороны) и отвечает за обучение по вопросам кибербезопасности в рамках Объединенного командно-штабного курса в Силах обороны Ирландии. Автор особенно благодарен доктору Рафаэлю Ф. Перлу за неоценимое руководство по структуре этой статьи и анализу, приведенного в ней. Email: d.kerigan-kyrou@abertay.ac.uk 